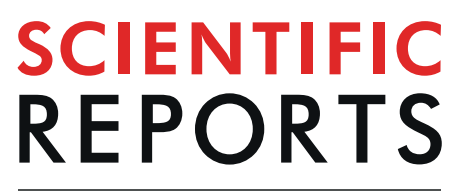

natureresearch

\title{
Thromboinflammatory changes in plasma proteome of pregnant women with PCOS detected by quantitative label-free proteomics
}

R. K. Arffman $\oplus^{1,6}$, M. Saraswatt $2,3,6$, S. Joenväärä2,3, M. Khatun ${ }^{1}$, R. Agarwal ${ }^{4}$, T. Tohmola ${ }^{2,3}$, I. Sundström-Poromaa $\mathbb{D}^{5}$, R. Renkonen ${ }^{2,3} \&$ T. T. Piltonen $\mathbb{1}^{1^{*}}$

Polycystic ovary syndrome (PCOS) is the most common endocrinological disorder of fertile-aged women. Several adverse pregnancy outcomes and abnormalities of the placenta have been associated with PCOS. By using quantitative label-free proteomics we investigated whether changes in the plasma proteome of pregnant women with PCOS could elucidate the mechanisms behind the pathologies observed in PCOS pregnancies. A total of 169 proteins with $\geq 2$ unique peptides were detected to be differentially expressed between women with PCOS $(n=7)$ and matched controls $(n=20)$ at term of pregnancy, out of which 35 were significant ( $p$-value $<0.05$ ). A pathway analysis revealed that networks related to humoral immune responses, inflammatory responses, cardiovascular disease and cellular growth and proliferation were affected by PCOS. Classification of cases and controls was carried out using principal component analysis, orthogonal projections on latent structure-discriminant analysis (OPLS-DA), hierarchical clustering, self-organising maps and ROC-curve analysis. The most significantly enriched proteins in PCOS were properdin and insulin-like growth factor II. In the dataset, properdin had the best predictive accuracy for PCOS (AUC =1). Additionally, properdin abundances correlated with AMH levels in pregnant women.

Polycystic ovary syndrome (PCOS) is a complex, heterogeneous and often underdiagnosed endocrine disorder. According to the International PCOS Guideline, the syndrome can be diagnosed if at least two of three of the following criteria are fulfilled after exclusion of other etiologies: oligo- or anovulation, clinical and/or biochemical hyperandrogenism and polycystic ovaries ${ }^{1}$. The estimated prevalence varies from $8-12 \%$ depending on the study population and applied criteria ${ }^{2-4}$. As PCOS has a strong metabolic and inflammatory side, it should be considered more than a mere gynaecological problem. Indeed, affected women are at increased risk for metabolic syndrome, type II diabetes and cardiovascular diseases ${ }^{5}$. Moreover, low-grade chronic inflammation is commonly detected in women with PCOS, and it has been linked to the development of insulin resistance and accelerated atherosclerosis 6 .

Due to the vast scientific interest in PCOS, it has become evident that affected women also present with high pregnancy- related morbidity and adverse offspring outcomes ${ }^{7,8}$. Affected women have a $3-4$ - fold increase in the risk of pregnancy-induced hypertension and pre-eclampsia and a 2 -fold higher risk for preterm delivery independent of BMI . Structural alterations of placentae from women with PCOS have been reported, even in uncomplicated pregnancies, possibly indicating abnormal placentation and defective placental function ${ }^{10,11}$.

Proteomic technologies have been used to study PCOS-related alterations in protein expression in the plasma, ovarian tissue, follicular fluid, adipose tissue and $\mathrm{T}$ cells ${ }^{12-16}$. A list of proteomic biomarkers for PCOS has also been published, showing an association with networks related to the coagulation system, cell cycle regulation, metabolism, apoptosis, immune system/inflammation, cell signalling, oxidative stress, insulin, adipose tissue

${ }^{1}$ Department of Obstetrics and Gynecology, PEDEGO Research Unit, Medical Research Center, Oulu University Hospital, University of Oulu, Oulu, Finland. ${ }^{2}$ Transplantation Laboratory, Haartman Institute, University of Helsinki, Helsinki, Finland. ${ }^{3} \mathrm{HUSLAB}$, Helsinki University Hospital, Helsinki, Finland. ${ }^{4}$ Department of Reproductive biology, All India Institute of Medical Sciences, Ansari Nagar, New Delhi, 110029, India. ${ }^{5}$ Department for Women's and Children's Health, Uppsala University, Uppsala, Sweden. ${ }^{6}$ These authors contributed equally: R. K. Arffman and M. Saraswat. *email: terhi.piltonen@oulu.fi 
regulation, cholesterol and cell structure ${ }^{17}$. Interestingly, the proteomics biomarkers detected in women with PCOS overlap with those detected in women with pre-eclampsia, a disorder defined by hypertension and proteinuria, often related to placental dysfunction ${ }^{18}$. It is important to note that all the previous proteomic analyses in women with PCOS have been conducted using samples from non-pregnant women, and to date, no proteomics studies have been published for pregnant women with PCOS. Given that the women with PCOS are at risk for adverse gestational outcomes, a proteomic analysis during pregnancy could clarify the mechanisms leading to these conditions. In general, pregnancy can be considered a stress test as well as a window of opportunity to estimate health risks in women later in life ${ }^{19}$. For PCOS, it could be possible to identify the affected women, especially those at risk for adverse health outcomes later in life, by discerning the differences in circulating proteins.

By adopting a quantitative label-free proteomics approach, plasma proteomes of samples from uncomplicated term pregnancies of non-obese women with PCOS were compared with those of controls matched for age and BMI. A total of 169 proteins with two or more unique peptides were differentially expressed between cases and controls, from which 35 passed the cut-off Mann-Whitney p-value of 0.05 . These proteins formed protein-protein interaction networks related to humoral immunity, inflammation and cardiovascular disease. The data were further analysed by the principal component analysis (PCA). To determine how well the proteomic analysis could classify the women with PCOS and controls and to identify possible biomarkers for PCOS, three parallel methods were used: orthogonal projections to latent structure-discriminant analysis (OPLS-DA), hierarchical clustering (HCA) and self-organizing maps (SOMs). We also found that the detected proteins correlated with several circulating hormones. It was also of interest to identify novel biomarkers that could be utilized in PCOS diagnostics. A ROC-curve analysis revealed that in the data set, complement factor properdin (properdin) was able to classify cases and controls with very high accuracy. Interestingly, properdin abundances correlated with AMH levels at the end of pregnancy.

\section{Results}

Metadata. Label-free quantitative proteomics was performed on seven plasma samples from pregnant women with PCOS at term and on 20 plasma samples from pregnant control women matched for age and BMI. All plasma samples were collected at the delivery ward when the women arrived to give birth. A schematic representation of the entire analysis process is depicted in Fig. 1. Patient demographics are presented in Table 1. Furthermore, plasma Anti-Müllerian hormone (AMH) and steroid hormone analysis results from the authors' previous study ${ }^{20}$ were added in the analyses as additional variables.

Proteomics in cases and controls. A total of 169 proteins with two or more unique peptides were identified, from which 35 passed the cut-off Mann-Whitney p-value of 0.05 . The fold-changes of the proteins with a $\mathrm{p}$-value $<0.05$ ranged from 13,3 to -3.81 . The proteins with two or more unique peptides detected and a Mann-Whitney p-value $<0.05$ as well as their mean abundances are listed in Table 2. The exact standardized protein abundances for each individual are listed in Supplementary Table 1.

Pathway analysis. The Ingenuity pathway analysis (IPA) network module was used to identify the protein interaction networks of proteins differentially expressed in pregnant women with PCOS compared to pregnant control women. Only the proteins passing the cut-off p-value of 0.05 from the Mann-Whitney analysis were used. Network analysis reveals shared functional and biological aspects between the proteins which makes it easier to interpret how the proteomic changes affect the body as a whole. The networks that were identified were related to humoral immune responses, inflammatory responses, cardiovascular disease and cellular growth and proliferation. Full lists of proteins in these two networks can be found in Supplementary Tables 2 and 3.

Principal component analysis (PCA). A PCA was done using Progenesis QI Proteomics to determine the principal axes on protein abundance variations in PCOS cases and controls. PCA reduces the data to its basic components so that patterns and clusters can be detected. The analysis with all the proteins with two or more unique peptides did not show distinct clustering (Fig. 2b), however, when PCA was carried out with only the proteins with two or more unique peptides and a Mann-Whitney $\mathrm{p}$-value $<0.05$ the cases and controls mostly separated along the X-axis (Fig. 2a), revealing that the proteomes of pregnant women with PCOS resemble each others.

Hierarchical clustering and SOM clustering. Protein abundance data of PCOS vs control (top 35 Mann-Whitney Passing proteins only) were used for hierarchical clustering (HCA) and self-organizing map (SOM) clustering analyses to determine which samples cluster together. Clustering analyses are unsupervised methods, so the only information provided is the protein abundance data, based on which the process clusters the individuals whose proteomes most resemble each other. In hierarchical clustering analysis 6/7 cases of PCOS clustered together (Fig. 3). In SOM clustering, however, all cases cluster next to each other (Fig. 4). This shows that based on only the protein abundances, unsupervised methods find enough similarities in proteomes of pregnant women with PCOS to cluster them together.

Orthogonal projections to latent structure-discriminant analysis (OPLS-DA). OPLS-DA modelling was used to identify proteins that can differentiate the cases from controls. OPLS-DA is a modelling technique that can perform binary comparisons. The modelling provides two values: ( $p$ ) is the magnitude of change of a given marker, and ( $p$ (corr)) depicts significance of the marker in binary comparison. Any experiment with a large number of measured variables can be modelled with OPLS-DA to filter out the most differing markers among the two groups. OPLS-DA can separate predictive and uncorrelated variance in binary comparisons. According to OPLS-DA, two proteins that passed the cutoff value of +0.65 or -0.65 for $p$ (corr) were enriched in 


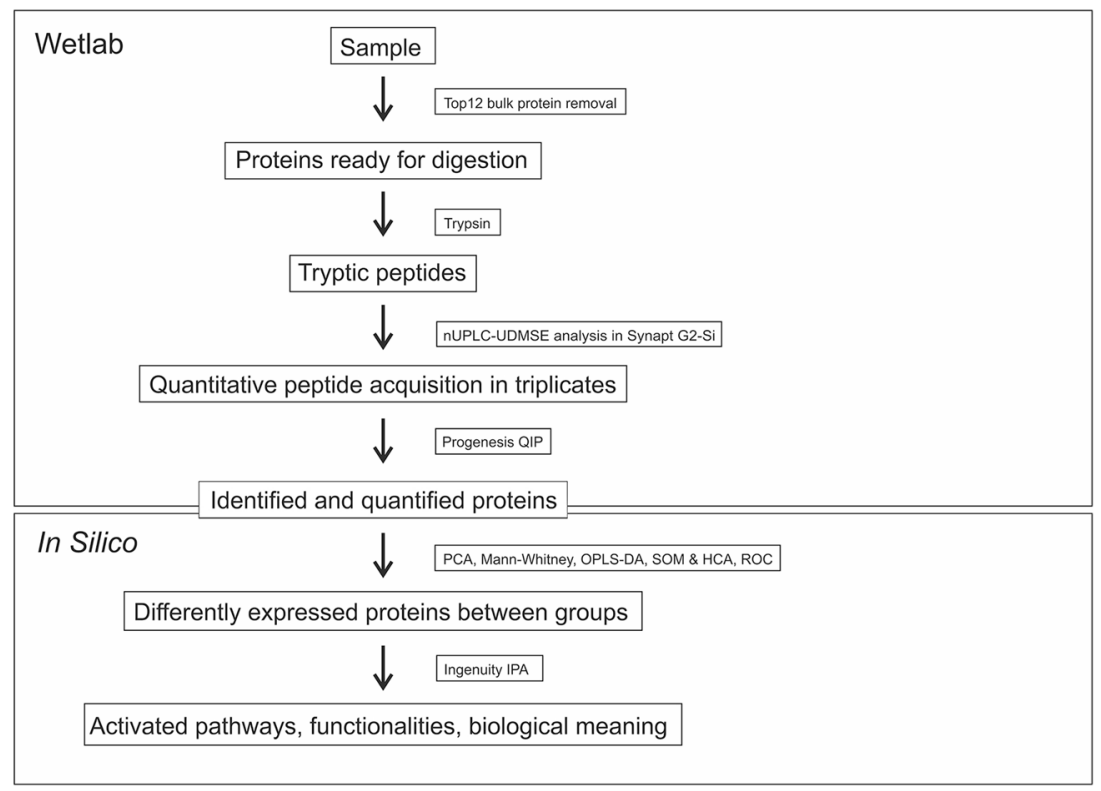

Figure 1. Quantitative Proteomics Analysis Workflow (see Methods for further information). Lithium-heparin plasma samples were depleted of the 12 most abundant proteins and digested with trypsin. Nanoflow ultrahigh performance liquid chromatography - Ultra-Definition Mass-spectrophotometry (nUPLC-UDMSE) was performed in triplicates. After acquisition, the data analysis was performed with Progenesis QI. Differences in protein abundances between groups were assessed by the Mann-Whitney U-test with a cut-off level set to $\mathrm{p}<0.05$. A network analysis by IPA was used to build protein interaction networks of proteins that differed between cases and controls and to provide a broader scope for interpretation regarding how the changes may affect the functions of the body. The Principal Component Analysis (PCA) was used to visualise the principal axes of protein abundance variations in cases and controls in order to define how much variation the sample classes has when compared and whether the cases and control separate from each others. A clustering analysis is an alternative technique to analyze the differences between groups as well as similarities within a group. Self-organizing maps (SOM) is an unsupervised data visualization technique that reduces the dimensions of data through the use of self-organising neural networks. Hierarchical clustering analysis (HCA) calculates the dissimilarity between individuals and builds a hierarchy of clusters. OPLS-DA was used to define differences between the groups and to identify the proteins with the highest discriminative power. These proteins were then used for the ROC-curve analysis to calculate AUC-values.

\begin{tabular}{|c|c|c|c|c|c|}
\hline \multirow[b]{2}{*}{ Variable } & \multicolumn{2}{|l|}{$\operatorname{PCOS}(\mathrm{N}=7)$} & \multicolumn{2}{|c|}{ Control $(\mathrm{N}=20)$} & \multirow[b]{2}{*}{ p-value } \\
\hline & Mean/Median & SD/IQR & Mean/Median & SD/IQR & \\
\hline Age, years & 32 & 4.7 & 32 & 3.8 & 0.802 \\
\hline Pre-pregnancy BMI, kg/m² & 21.79 & 3.98 & 23.36 & 3.50 & 0.310 \\
\hline Gestational weight gain $(\mathrm{kg})$ & 11.0 & 4.3 & 12.5 & 3.1 & 0.497 \\
\hline Gestational length,days & 279 & 11 & 286 & 6 & $0.045^{*}$ \\
\hline Systolic BP, mmHg & 123 & 11 & 125 & 10 & 0.7567 \\
\hline Diastolic BP, mmHg & 76 & 7 & 77 & 6 & 0.871 \\
\hline Birthweight, g & 3430 & 421 & 3863 & 573 & 0.161 \\
\hline Cesarean section (\%) & 14,3 & - & 25 & - & 0.656 \\
\hline $\mathrm{AMH}(\mathrm{ng} / \mathrm{mL})$ & 1.60 & $0.93-3.54$ & 0.91 & $0.49-1.14$ & $0.013 *$ \\
\hline Testosterone (nmol/L) & 3.48 & $2.77-5.08$ & 2.54 & $1.68-3.74$ & 0.166 \\
\hline Estradiol (nmol/L) & 80.59 & 17.76 & 71.35 & 39.7 & 0.302 \\
\hline
\end{tabular}

Table 1. Clinical characteristics of the study subjects. BMI, body-mass index; BP, blood pressure; SD, standard deviation; IQR, inter-quartile range; N, number of participants; AMH, Anti-Müllerian hormone.

the plasma of pregnant women with PCOS: properdin (CFP) ( $\mathrm{p}$ (corr) value $=-0.850)$ and insulin-like growth factor II (IGF-II) ( $\mathrm{p}$ (corr) $=-0.691)$, indicating them as potential discriminant markers in our dataset.

ROC curve analysis. To identify the proteins that could be used to distinguish the cases from controls, a ROC curve analysis was performed using Metaboanalyst analysis tool ${ }^{21}$. The top 35 plasma proteins and $\mathrm{AMH}-$ levels were used for calculating ROC curves for individual markers as well as combination ROC curves for 


\begin{tabular}{|c|c|c|c|c|c|c|c|c|c|}
\hline \multirow[b]{2}{*}{ Protein name } & \multirow[b]{2}{*}{ UniProt ID } & \multirow[b]{2}{*}{$\begin{array}{l}\text { Peptide } \\
\text { count }\end{array}$} & \multirow[b]{2}{*}{$\begin{array}{l}\text { Unique } \\
\text { peptides }\end{array}$} & \multirow{2}{*}{$\begin{array}{l}\text { Mann- } \\
\text { Whitney } \\
\text { P-value }\end{array}$} & \multirow[b]{2}{*}{$\begin{array}{l}\text { Max fold } \\
\text { change }\end{array}$} & \multicolumn{2}{|c|}{ Normalized abundance } & \multicolumn{2}{|l|}{ Raw abundance } \\
\hline & & & & & & $\begin{array}{l}\text { Control } \\
(\text { mean } \pm \text { SD })\end{array}$ & $\begin{array}{l}\text { PCOS } \\
(\text { mean } \pm \text { SD })\end{array}$ & $\begin{array}{l}\text { Control } \\
(\text { mean } \pm S D)\end{array}$ & $\begin{array}{l}\text { PCOS } \\
(\text { mean } \pm \text { SD })\end{array}$ \\
\hline Properdin (CFP) & P27918 & 4 & 3 & 6,02E-05 & 13,3 & $9871 \pm 8885$ & $131111 \pm 60591$ & $8907 \pm 7368$ & $81473 \pm 41346$ \\
\hline $\begin{array}{l}\text { Actin_cytoplasmic } 1 \\
\text { (ACTB) }\end{array}$ & P60709;P63261 & 12 & 3 & 6,91E-03 & 3,1 & $2019 \pm 1857$ & $6287 \pm 6080$ & $1747 \pm 1199$ & $3588 \pm 2964$ \\
\hline $\begin{array}{l}\text { Insulin-like growth factor } \\
\text { II (IGF2) }\end{array}$ & P01344 & 2 & 2 & 4,97E-04 & 2,6 & $38381 \pm 23687$ & $100387 \pm 34863$ & $34863 \pm 17388$ & $64047 \pm 30921$ \\
\hline Platelet factor 4 (PF4) & P02776;P10720 & 6 & 6 & 2,19E-03 & 2,0 & $96379 \pm 83088$ & $193262 \pm 86578$ & $89987 \pm 54166$ & $121068 \pm 65809$ \\
\hline $\begin{array}{l}\text { F-box/LRR-repeat protein } \\
6 \text { (FBXL6) }\end{array}$ & Q8N531 & 2 & 2 & $3,64 \mathrm{E}-03$ & 1,8 & $163796 \pm 81585$ & $297700 \pm 135684$ & $151970 \pm 69540$ & $192129 \pm 120097$ \\
\hline $\begin{array}{l}\text { Protein SAA2-SAA4 } \\
\text { (SAA2-SAA4) }\end{array}$ & $\begin{array}{l}\text { A0A096LPE2; } \\
\text { P35542;P0DJI9 }\end{array}$ & 11 & 8 & $1,84 \mathrm{E}-03$ & 1,8 & $94904 \pm 30973$ & $166255 \pm 61245$ & $88176 \pm 28302$ & $106182 \pm 50352$ \\
\hline $\begin{array}{l}\text { Platelet basic protein } \\
\text { (PPBP) }\end{array}$ & P02775 & 8 & 7 & $9,35 \mathrm{E}-03$ & 1,6 & $126680 \pm 61697$ & $207258 \pm 69378$ & $114575 \pm 40132$ & $129752 \pm 60820$ \\
\hline $\begin{array}{l}\text { Coagulation factor XII } \\
\text { (F12) }\end{array}$ & P00748 & 15 & 11 & 4,97E-04 & 1,6 & $168494 \pm 49967$ & $266963 \pm 58132$ & $164621 \pm 67246$ & $163966 \pm 46991$ \\
\hline Fibulin-1 (FBLN1) & $\mathrm{P} 23142$ & 24 & 19 & 6,91E-03 & 1,5 & $186638 \pm 76342$ & $283480 \pm 90281$ & $177325 \pm 73434$ & $178048 \pm 73724$ \\
\hline $\begin{array}{l}\text { Thrombospondin-1 } \\
\text { (THBS1) }\end{array}$ & P07996 & 9 & 6 & $6,91 \mathrm{E}-03$ & 1,5 & $40101 \pm 11892$ & $60276 \pm 25891$ & $38058 \pm 12812$ & $41024 \pm 30970$ \\
\hline Ensconsin (MAP7) & Q14244 & 3 & 3 & 2,17E-02 & 1,4 & $140935 \pm 43737$ & $191963 \pm 55106$ & $134780 \pm 49697$ & $119405 \pm 44316$ \\
\hline Clusterin (CLU) & P10909 & 41 & 34 & $1,28 \mathrm{E}-03$ & 1,4 & $104524 \pm 182056$ & $1411565 \pm 233890$ & $996799 \pm 265839$ & $899511 \pm 341864$ \\
\hline $\begin{array}{l}\text { Complement factor } \\
\text { H-related protein } 4 \\
\text { (CFHR4) }\end{array}$ & Q92496 & 2 & 2 & $4,07 \mathrm{E}-02$ & 1,3 & $6025 \pm 3254$ & $8120 \pm 3551$ & $5561 \pm 2350$ & $5138 \pm 2453$ \\
\hline $\begin{array}{l}\text { Apolipoprotein A-IV } \\
\text { (APOA4) }\end{array}$ & P06727 & 56 & 54 & $2,48 \mathrm{E}-02$ & 1,3 & $1342773 \pm 378828$ & $1787655 \pm 541403$ & $1259649 \pm 367488$ & $1165558 \pm 577026$ \\
\hline $\begin{array}{l}\text { Apolipoprotein C-III } \\
\text { (APOC3) }\end{array}$ & P02656 & 26 & 23 & $2,48 \mathrm{E}-02$ & 1,3 & $779875 \pm 355305$ & $1019474 \pm 264894$ & $739388 \pm 350789$ & $627452 \pm 207791$ \\
\hline $\begin{array}{l}\text { Alpha-1B-glycoprotein } \\
\text { (A1BG) }\end{array}$ & P04217 & 94 & 83 & $2,17 \mathrm{E}-02$ & 1,3 & $5953838 \pm 1342139$ & $7716950 \pm 1858329$ & $5646416 \pm 1498040$ & $4962091 \pm 2219956$ \\
\hline $\begin{array}{l}\text { Inter-alpha-trypsin } \\
\text { inhibitor heavy chain H2 } \\
\text { (ITIH2) }\end{array}$ & P19823 & 94 & 82 & $3,64 \mathrm{E}-03$ & 1,3 & $3229720 \pm 548599$ & $4100130 \pm 965612$ & $3087860 \pm 821714$ & $2685395 \pm 1383517$ \\
\hline Hemopexin (HPX) & $\begin{array}{l}\text { P02790;Q2M389 } \\
\text { Q8N987;Q9NZ08 }\end{array}$ & 122 & 111 & $1,44 \mathrm{E}-02$ & 1,3 & $7363912 \pm 1596736$ & $9221228 \pm 2118666$ & $7115877 \pm 2417683$ & $5933958 \pm 2625698$ \\
\hline $\begin{array}{l}\text { Inter-alpha-trypsin } \\
\text { inhibitor heavy chain H1 } \\
\text { (ITIH1) }\end{array}$ & P19827 & 79 & 70 & $3,19 \mathrm{E}-02$ & 1,2 & $3496796 \pm 808572$ & $4264955 \pm 1024208$ & $3322647 \pm 963914$ & $2795958 \pm 1499041$ \\
\hline Apolipoprotein E (APOE) & P02649 & 48 & 45 & $2,48 \mathrm{E}-02$ & 1,2 & $1265005 \pm 264966$ & $1521778 \pm 301299$ & $1207847 \pm 350338$ & $960169 \pm 347148$ \\
\hline $\begin{array}{l}\text { Apolipoprotein C-IV } \\
\text { (APOC4) }\end{array}$ & P55056 & 9 & 8 & $2,48 \mathrm{E}-02$ & 1,2 & $89509 \pm 50207$ & $107081 \pm 28316$ & $81235 \pm 31210$ & $66879 \pm 24291$ \\
\hline Plasminogen (PLG) & $\begin{array}{l}\text { P00747;Q15195; } \\
\text { Q02325;P35900 }\end{array}$ & 103 & 93 & $3,19 \mathrm{E}-02$ & 1,2 & $3257229 \pm 949755$ & $3823210 \pm 676537$ & $3098101 \pm 1041808$ & $2449869 \pm 996846$ \\
\hline Vitronectin (VTN) & P04004 & 79 & 62 & 3,19E-02 & 1,2 & $2833870 \pm 532068$ & $3299916 \pm 652184$ & $2721551 \pm 767587$ & $2111094 \pm 875460$ \\
\hline $\begin{array}{l}\text { Complement component } \\
\text { C8 alpha chain (C8A) }\end{array}$ & P07357 & 29 & 25 & $4,58 \mathrm{E}-02$ & $-1,2$ & $471877 \pm 74769$ & $409700 \pm 99288$ & $458636 \pm 142589$ & $266387 \pm 142378$ \\
\hline $\begin{array}{l}\text { Complement component } \\
\text { C8 beta chain (C8B) }\end{array}$ & P07358 & 30 & 25 & $3,61 \mathrm{E}-02$ & $-1,2$ & $673193 \pm 146055$ & $574634 \pm 243926$ & $649089 \pm 200788$ & $389647 \pm 289951$ \\
\hline $\begin{array}{l}\text { Carboxypeptidase B2 } \\
\text { (CPB2) }\end{array}$ & Q96IY4 & 13 & 11 & $1,66 \mathrm{E}-02$ & $-1,2$ & $210142 \pm 48905$ & $174108 \pm 43031$ & $200478 \pm 61439$ & $114195 \pm 61836$ \\
\hline $\begin{array}{l}\text { Serum paraoxonase/ } \\
\text { arylesterase } 1 \text { (PON1) }\end{array}$ & P27169 & 27 & 23 & $2,81 \mathrm{E}-02$ & $-1,3$ & $1370720 \pm 411430$ & $1070315 \pm 482501$ & $1335219 \pm 518580$ & $722929 \pm 570982$ \\
\hline $\begin{array}{l}\text { Zinc-alpha-2-glycoprotein } \\
\text { (AZGP1) }\end{array}$ & P25311 & 18 & 16 & $4,07 \mathrm{E}-02$ & $-1,3$ & $262328 \pm 64339$ & $199592 \pm 56997$ & $256660 \pm 92476$ & $129727 \pm 64001$ \\
\hline $\begin{array}{l}\text { Prostaglandin-H2 } \\
\text { D-isomerase (PTGDS) }\end{array}$ & P41222 & 3 & 2 & $4,29 \mathrm{E}-03$ & $-1,5$ & $7234 \pm 1724$ & $4701 \pm 1943$ & $6932 \pm 2207$ & $2910 \pm 1249$ \\
\hline $\begin{array}{l}\text { Glyceraldehyde-3- } \\
\text { phosphate dehydrogenase } \\
\text { (GAPDH) }\end{array}$ & P04406 & 4 & 4 & $4,58 \mathrm{E}-02$ & $-1,8$ & $12975 \pm 14276$ & $7261 \pm 2383$ & $11191 \pm 8804$ & $4770 \pm 3123$ \\
\hline $\begin{array}{l}\text { Complement factor } \\
\text { H-related protein } 5 \\
\text { (CFHR5) }\end{array}$ & Q9BXR6 & 4 & 2 & $2,81 \mathrm{E}-02$ & $-1,8$ & $9172 \pm 4751$ & $5084 \pm 2454$ & $9080 \pm 5239$ & $3449 \pm 2385$ \\
\hline Cystatin-C (CST3) & P01034 & 3 & 2 & 5,04E-03 & $-1,9$ & $24739 \pm 10617$ & $13244 \pm 4178$ & $24523 \pm 13612$ & $8542 \pm 4398$ \\
\hline Granzyme M (GZMM) & P51124 & 2 & 2 & 2,19E-03 & $-3,3$ & $171820 \pm 102607$ & $52349 \pm 80914$ & $165486 \pm 97526$ & $41860 \pm 75989$ \\
\hline $\begin{array}{l}\text { Embryonic growth/ } \\
\text { differentiation factor } 1 \\
\text { (GDF1) }\end{array}$ & P27539 & 2 & 2 & $2,17 \mathrm{E}-02$ & $-3,8$ & $35570 \pm 90017$ & $9334 \pm 6358$ & $27475 \pm 55416$ & $6343 \pm 6445$ \\
\hline
\end{tabular}

Table 2. List of proteins that were differentially abundant $(\mathrm{p}<0.05)$ in the plasma of pregnant women at term with PCOS compared with age and BMI matched controls. 
a.

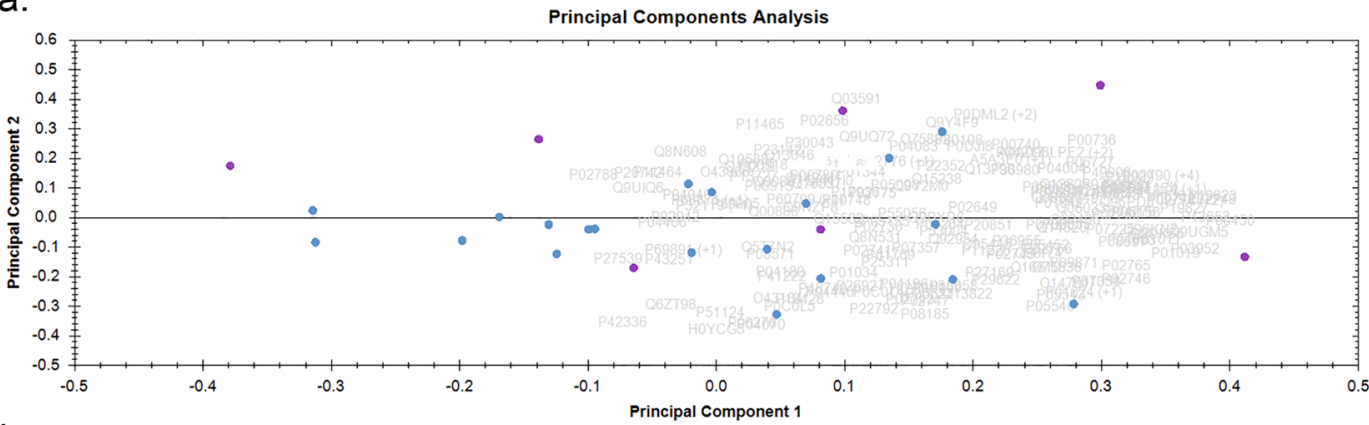

b.

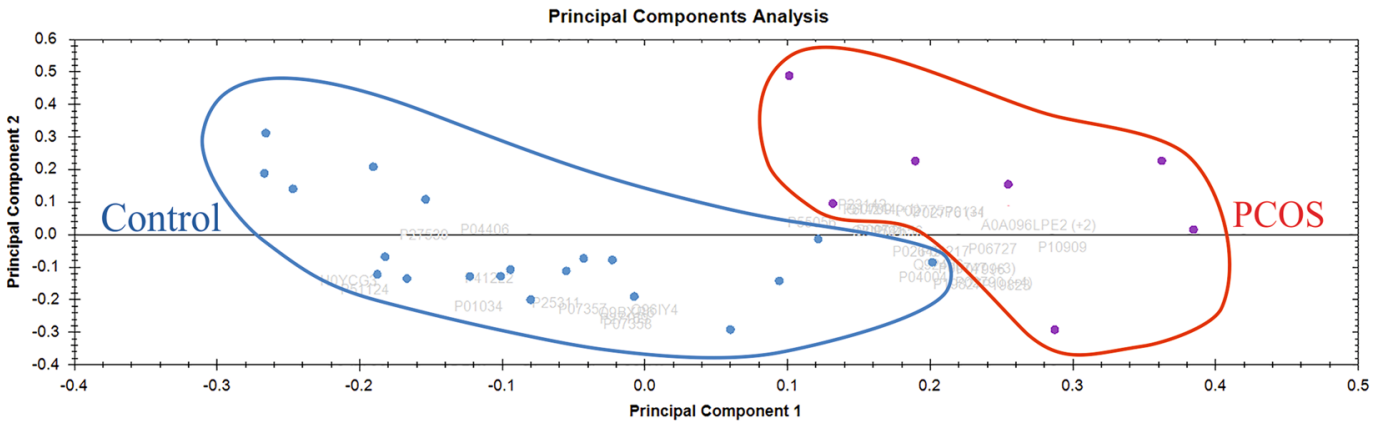

Figure 2. Principal component analysis. Purple dots represent PCOS cases (circled in red) and blue dots the controls (circled in blue). (a) All differentially expressed proteins with $\geq 2$ unique peptides are presented (b) Only proteins passing the cut-off of $\mathrm{p}<0.05$ for Mann-Whitney test are depicted. The cases and controls mostly cluster separately along the $\mathrm{x}$-axis.

sets of biomarkers by a support vector machine algorithm (Fig. 5a and Suppl. Table 4). Properdin alone had the best predictive accuracy (AUC-value = 1, Fig. 5c) but IGF-2 also performed well (Fig. 5b). Of note, properdin was also the top protein found by OPLS-DA in the dataset. This serves as the orthogonal statistical validation of the OPLS-DA modelling and non-parametric testing.

Correlation analysis. In order to see which clinical parameters correlated with protein abundances measured with LC-MS, we used clinical data as well as steroid hormone and AMH values form our previous study ${ }^{20}$. All significant correlations are listed in Table 3. Interestingly, properdin levels correlated positively with AMH levels $(r=0.417, p=0.0383)$. As AMH can be considered a marker for antral follicle count, high properdin levels may be linked with polycystic ovarian morphology. The strongest correlation was detected between inactive dipeptyl peptidase 10 (DPP10) and testosterone $(\mathrm{r}=0.700, \mathrm{p}<0.001)$.

\section{Discussion}

PCOS affects around $8-12 \%$ of the female population, making it one of the most common endocrinological disorders worldwide ${ }^{2-4}$. Although the affected women suffer from reproductive and metabolic dysfunction, the syndrome often remains undiagnosed ${ }^{22}$. PCOS is a risk factor for adverse pregnancy outcomes, such as pregnancy induced hypertension, pre-eclampsia, prematurity and gestational diabetes, but the underlying mechanisms remain unclear ${ }^{7,9}$. During pregnancy major metabolic and inflammatory changes occur in the female body. To determine whether these responses are affected by PCOS, plasma samples from uncomplicated term pregnancies from non-obese women with PCOS and matched controls were compared using label-free quantitative proteomics. To the authors' knowledge, this is the first study to assess the plasma proteome of pregnant women with PCOS.

The analysis indicated that 35 proteins were significantly differentially expressed between the cases and the controls. Most of the proteins were associated with networks related to inflammation, humoral immunity and cardiovascular disease. Amongst these were some proteins previously detected in non-pregnant women with PCOS, but proteins that have not been associated with PCOS previously were also identified. SOM clustering and hierarchical clustering analyses revealed that the PCOS cases cluster close to each other. The support vector machine based ROC analysis was used to identify individual or combinations of proteins that could best classify cases from controls, and it revealed that properdin (CFP) alone provided the best prediction for PCOS diagnosis in thedataset.

Several of the proteins now identified in pregnant women with PCOS have been reported to be differentially expressed in non-pregnant women with PCOS as well, including increased levels of insulin growth factor II (IGF2), platelet factor 4 (PF4), serum amyloid A (SAA), fibulin-1 (FBL1), apolipoprotein A4 (APOA4) and alpha-1B-glycoprotein (A1BG) and decreased levels of zinc-alpha-2-glycoprotein (AZGP1) and serum paraoxonase/arylesterase $1(\mathrm{PON} 1)^{23-27}$. In contrast to this finding, for non-pregnant women with PCOS, serum thrombospondin-1 (THBS1) levels have been reported to be lower ${ }^{28}$. Some of the proteins that were shown to be 


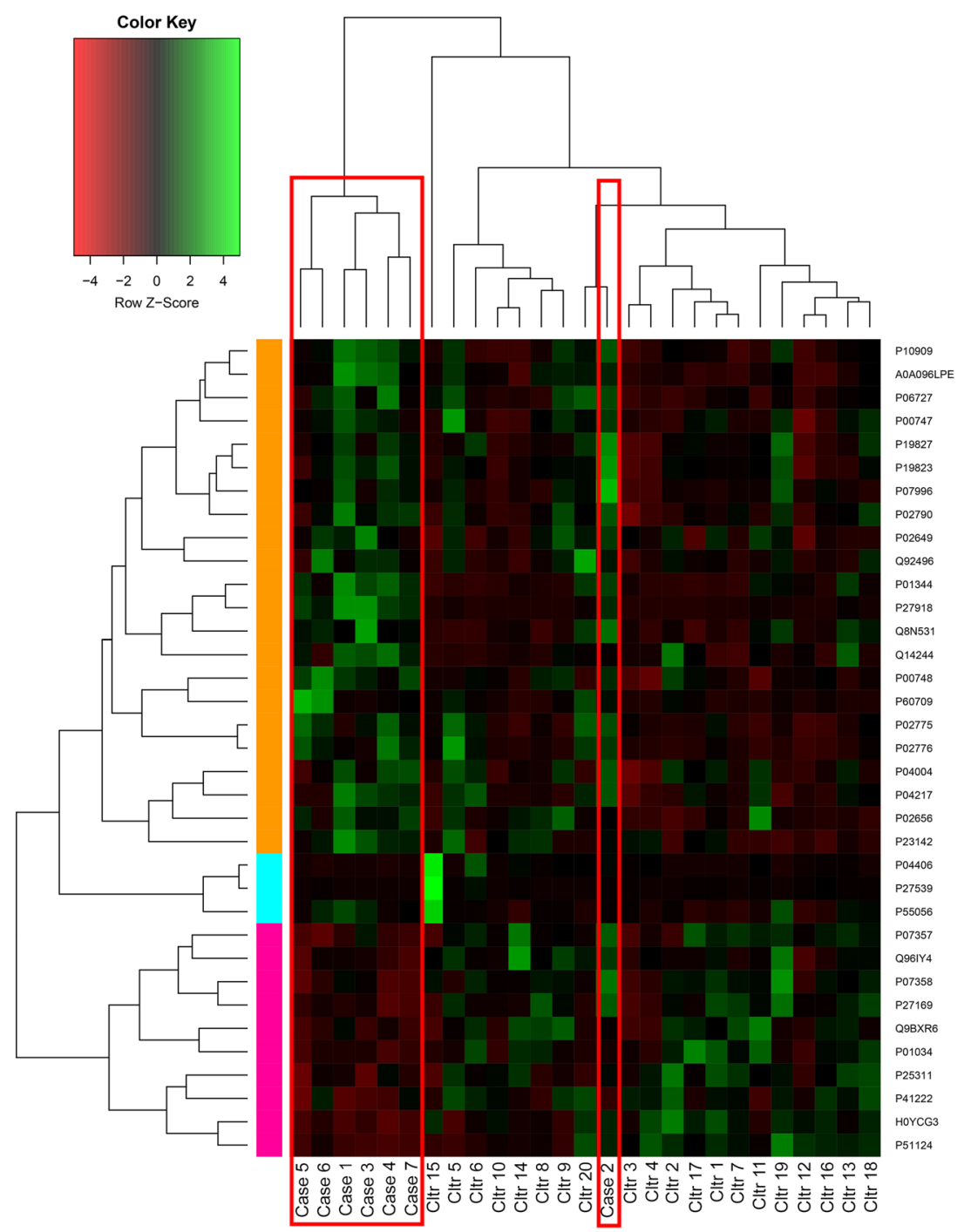

Figure 3. Hierarchical clustering analysis (HCA) of the 35 differentially expressed proteins in cases and controls. $5 / 6$ of the cases clustered together.

increased in the plasma of pregnant women with PCOS in the present study have been detected to be decreased in the follicular fluid of women with $\mathrm{PCOS}^{14}$. Interestingly, all these proteins are involved in thrombosis, inflammation and/or metabolism.

Indeed, the network analysis revealed that a vast majority of the differentially expressed proteins belonged to networks related to humoral responses, inflammatory responses, cardiovascular disease, lipid metabolism and cellular growth and proliferation. Even a normal pregnancy is an acquired hypercoagulable and inflammatory state ${ }^{29,30}$. The concentrations of coagulation factors increase and fibrinolysis and anticoagulatory factors decrease during gestation ${ }^{29}$. Furthermore, insulin sensitivity decreases by $50-60 \%^{31}$. All these changes are mandatory for the mother to adapt to pregnancy and on the other hand, a rigorous control of these factors is critical for a healthy pregnancy. Conditions that predispose to thrombosis, inflammation or insulin resistance may affect this fine balance, leading to suboptimal implantation and placentation and possibly complications during pregnancy.

The protein levels of IGF-2 were significantly higher in women with PCOS in our dataset. IGF-2 has been linked to placental function in several studies: Igf2 overexpression in mice leads to overgrowth of both the placenta and the fetus ${ }^{32}$ and deletion of the placental-specific Igf2 leads to reduction in placental and fetal weight and decreased transport of nutrients and reduced diffusion capacity ${ }^{33,34}$. In quinea pigs, administration of IGF-II to the mother in early-pregnancy increases placental functional capacity and weight of the fetus and the placenta ${ }^{35}$. Women with PCOS have a higher risk for large for large for gestational age (LGA) infants in general $^{8}$, which could be partly explained with higher IGF-2 levels in their circulation. In our dataset, IGF-2 protein levels at the end of pregnancy did not correlate with fetal weight, however, we did not have any LGA infants in the PCOS group. Unfortunately, we did not have the information for placental weight to correlate with the IGF-2 levels.

Women with PCOS have a 3-4-fold higher risk for developing pre-eclampsia (PE) during pregnancy ${ }^{9}$. Pre-eclampsia is characterised by hypertension $(\geq 140 / 90 \mathrm{mmHg})$ and proteinuria $(>300 \mathrm{mg} /$ day) after the 20 th 


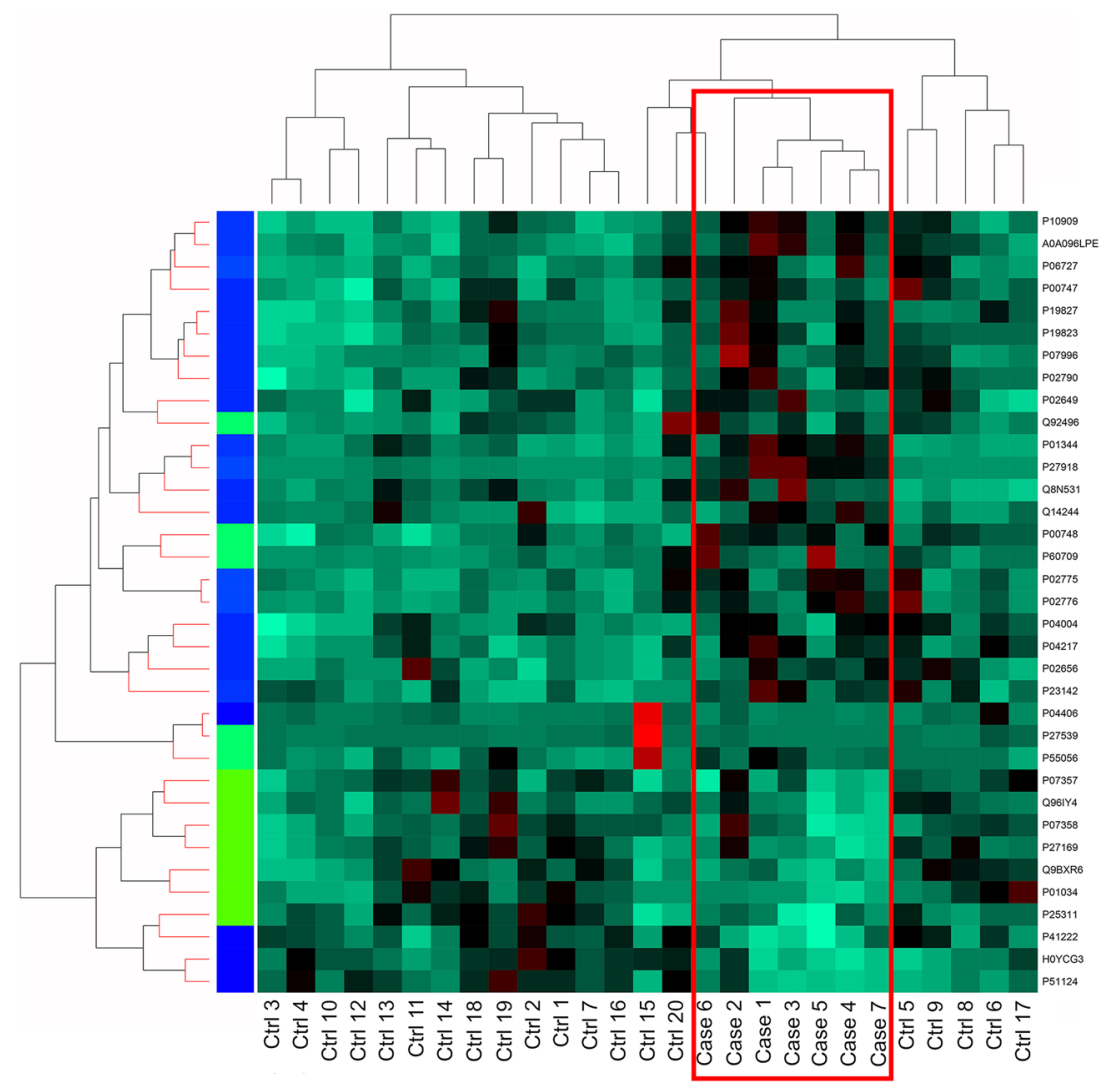

Figure 4. Self-organizing map (SOM) clustering of the 35 differentially expressed proteins in cases and controls. All cases clustered together.

week of gestation. PE is assumed to stem from defective vascular function and placentation leading to hypoxia of the placenta, the release of soluble factors and over time, to generalised inflammation and progressive endothelial damage $^{36}$. It has been reported that the proteomic markers of PCOS overlap with those identified in pre-eclamptic patients ${ }^{18}$, however, none of the PCOS studies utilised in the systematic review included data of pregnant women. Like PCOS, pre-eclampsia is a multi-systemic syndrome, where complex pathophysiological changes, including endothelial dysfunction, inflammation, activation of coagulation and metabolic changes are prominent features. Taking all this into account, it is not surprising that many of the proteins that were differentially expressed between pregnant PCOS cases and controls in the dataset have also been linked to pre-eclampsia, e.g. properdin, insulin-like growth factor 2 (IGF2), PF4, coagulation factor XII (F12), FBL1, apolipoprotein C3 (APOC3), hemopexin (HPX), apolipoprotein E (APOE), PLG, vitronectin (VTN), ZAG1, prostaglandin-H2 D-isomerase (PTGDS) and the complement component $\mathrm{C} 8$ alpha chain $(\mathrm{C} 8 \mathrm{~A})^{18}$. It is interesting to note that these differences in circulating proteins were detected even though the women with PCOS included in our study had no signs of pre-eclampsia and a histological examination of their placentas revealed no abnormalities. Whether the presence of these markers can explain the increased risk of pregnancy complications or can be used to predict cardiometabolic risk later in life requires further research.

Complement factor properdin is a positive regulator of the alternative pathway but it can also act as an independent complement activator ${ }^{37}$. Properdin also seems to control platelet aggregation by exacerbating thromboinflammation ${ }^{38}$. In this dataset, properdin was enriched in the plasma of pregnant women with PCOS compared with controls. Disturbances in complement activation have been detected in women with PCOS previously, as complement factor $\mathrm{C} 3$ has been reported to correlate with traditional cardiovascular disease risk factors in these women, most importantly with insulin resistance ${ }^{39,40}$. Excessive complement activation during pregnancy has been linked to many pregnancy complications, such as pre-eclampsia, preterm birth and pregnancy-induced hypertension ${ }^{41}$. Properdin also had the highest $\mathrm{p}$ (corr)-value according to the OPLS-DA analysis, and the ROC-curve analysis showed that properdin alone could classify the cases and controls with high accuracy. Interestingly, properdin levels correlated with AMH levels, indicating a possible link between these two proteins. Unfortunately, the increase in properdin levels could not be confirmed using commercially available ELISAs (data not shown). This is most likely due to the fact that upon a freeze-thawing process properdin forms tight aggregates that resist even highly reducing conditions ${ }^{38}$. Due to the harsh sample reducing steps of LC/MS, it is well suited for the detection of properdin, unlike ELISA which preserves the structure of the antigen.

Correlation analysis of the identified protein abundances with clinical parameters, steroid hormones or AMH revealed several significant correlations. The most significant correlations were observed with testosterone, such as between testosterone and inactive dipeptidyl peptidase (DPP10; $\mathrm{r}=0.700)$. DPP10 genes have previously been 

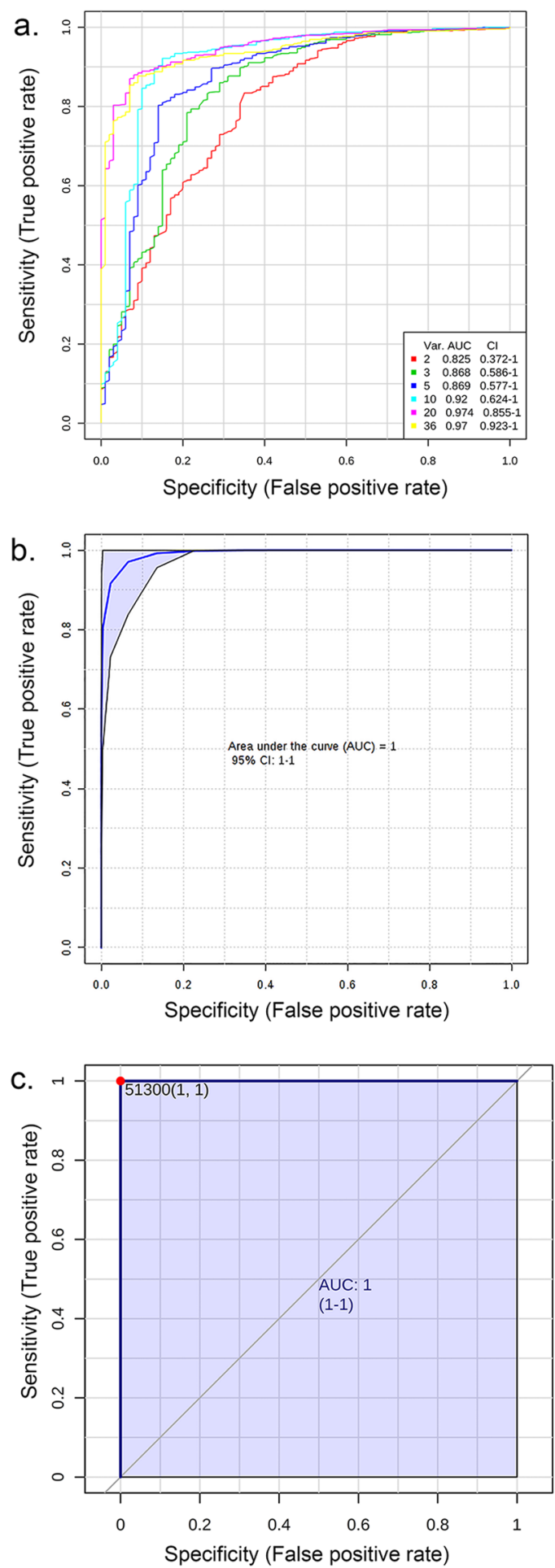

Figure 5. ROC-curve analysis using individual or a combination of proteins. (a) Combination ROC-curves calculated by MetaboAnalyst 4.0. The best AUC-value was reached using all the identified 35 proteins and $\mathrm{AMH}$ (yellow, AUC: 0.97). See Suppl. Table 4 for proteins used for creation of the curves. (b) AUC-curve of IGF-2 AUC: 0.937 . c. An AUC-curve of properdin alone can classify cases and controls perfectly, AUC: 1 .

reported to be enriched in patients with autism ${ }^{42}$, a condition which incidence has been reported to be higher in women with PCOS and their offspring ${ }^{43}$. Androstenedione levels correlated negatively with sex-hormone binding globulin, cardiovascular protective factors (e.g. kallistatin ${ }^{44}$ ) and lipolytic factors (e.g. zinc-alpha -2-glycoprotein ${ }^{45}$ ), and both androstenedione and testosterone correlated with several complement factors, indicating that androgens affect plasma proteome of pregnant women. 


\begin{tabular}{|c|c|c|c|c|c|c|c|c|c|}
\hline Protein & Accession & АМH & Androstenedione & Testosterone & Progesterone & Estradiol & Estriol & Estrone & $\begin{array}{l}\text { Estrone-3- } \\
\text { sulphate }\end{array}$ \\
\hline Granzyme M & P51124 & $-0.574(0.0027)$ & $-0.444(0.0262)$ & & $-0.424(0.0349)$ & & & & \\
\hline Unknown & H0YCG3 & $-0.541(0.0053)$ & $-0.505(0.0101)$ & & $-0.486(0.0138)$ & $-0.500(0.0109)$ & & & \\
\hline Unknown & H0YJW9 & $-0.498(0.0113)$ & $-0.589(0.0020)$ & & $-0.483(0.0144)$ & $-0.403(0.0455)$ & & & \\
\hline $\begin{array}{l}\text { Complement component } \\
\text { C8 gamma chain }\end{array}$ & P07360 & $-0.431(0.0317)$ & $-0.530(0.0065)$ & & & $-0.436(0.0292)$ & $-0.403(0.0455)$ & & \\
\hline Properdin & P27918 & $0.417(0.0383)$ & & & & & & & \\
\hline Serum amyloid $\mathrm{P}$ & P02743 & $-0.405(0.0443)$ & & & & & & & \\
\hline $\begin{array}{l}\text { Fanconi associated } \\
\text { nuclease }\end{array}$ & Q9Y2M0 & $-0.404(0.0452)$ & & & & & & & \\
\hline Heparin cofactor 2 & P05546 & $-0.402(0.0463)$ & & & $-0.410(0.0416)$ & $-0.430(0.0319)$ & & & \\
\hline Fetuin-B & Q9UGM5 & $-0.397(0.0493)$ & $-0.404(0.0451)$ & & $-0.435(0.0298)$ & & & & \\
\hline $\begin{array}{l}\text { C4b-binding protein } \\
\text { alpha chain }\end{array}$ & P04003 & & $-0.583(0.0022)$ & & & & & & \\
\hline Apolipoprotein C-III & P02656 & & $0.525(0.0071)$ & $0.645(4.96 \mathrm{E}-04)$ & $0.430(0.0319)$ & $0.507(0.0097)$ & & & \\
\hline $\begin{array}{l}\text { Insulin-like growth } \\
\text { factor-binding protein } \\
\text { complex acid labile } \\
\text { subunit }\end{array}$ & P35858 & & $-0.523(0.0073)$ & & $-0.459(0.0209)$ & & & & \\
\hline Ficolin-3 & O75636 & & $-0.466(0.0190)$ & & $-0.442(0.0270)$ & & & & \\
\hline $\begin{array}{l}\text { Keratin type I } \\
\text { cytoskeletal } 9\end{array}$ & P35527 & & $-0.434(0.0304)$ & & $-0.526(0.0070)$ & & & & \\
\hline $\begin{array}{l}\text { Phosphatidylinositol } \\
\text { 4.5-bisphosphate } \\
\text { 3-kinase catalytic subunit } \\
\text { alpha }\end{array}$ & P42336 & & $-0.430(0.0317)$ & & & & & & \\
\hline $\begin{array}{l}\text { Prostaglandin- } \mathrm{H} 2 \\
\text { D-isomerase }\end{array}$ & $\mathrm{P} 41222$ & & $-0.422(0.0357)$ & & $-0.399(0.0483)$ & & & & \\
\hline $\begin{array}{l}\text { Pregnancy-specific beta- } \\
\text { 1-glycoprotein } 3\end{array}$ & Q16557 & & $-0.417(0.0379)$ & & & & $-0.513(0.0088)$ & & \\
\hline Kallistatin & P29622 & & $-0.416(0.0384)$ & & & & & & \\
\hline $\begin{array}{l}\text { Sex hormone-binding } \\
\text { globulin }\end{array}$ & P04278 & & $-0.416(0.0388)$ & & & & $-0.406(0.0442)$ & & \\
\hline Tetranectin & P05452 & & $-0.413(0.0402)$ & & $-0.555(0.0040)$ & $-0.412(0.0407)$ & $-0.424(0.0347)$ & & \\
\hline Complement C3 & $\begin{array}{l}\text { P01024; } \\
\text { Q96MT0 }\end{array}$ & & $-0.411(0.0415)$ & & & & & & \\
\hline $\begin{array}{l}\text { Zinc-alpha-2- } \\
\text { glycoprotein }\end{array}$ & P25311 & & $-0.400(0.0474)$ & & $-0.477(0.0158)$ & & & & \\
\hline $\begin{array}{l}\text { Inactive dipeptidyl } \\
\text { peptidase } 10\end{array}$ & Q8N608 & & & $0.700(9.96 \mathrm{E}-05)$ & & $0.646(0.0005)$ & & $0.479(0.0155)$ & \\
\hline Attractin & O75882 & & & 0.566 (3.17E-03) & & & & & \\
\hline $\begin{array}{l}\text { Inter-alpha-trypsin } \\
\text { inhibitor heavy chain } \mathrm{H} 4\end{array}$ & Q14624 & & & $0.560(3.62 \mathrm{E}-03)$ & & & & & \\
\hline $\begin{array}{l}\text { Complement factor } \\
\text { H-related protein } 5\end{array}$ & Q9BXR6 & & & $0.404(4.52 \mathrm{E}-02)$ & & & & & \\
\hline Pappalysin-1 & Q13219 & & & & $0.568(0.0031)$ & & & & \\
\hline Platelet factor 4 & P02766 & & & & $-0.530(0.0064)$ & & & & \\
\hline $\begin{array}{l}\text { Vitamin K-dependent } \\
\text { protein C }\end{array}$ & P04070 & & & & $-0.460(0.0207)$ & $-0.430(0.0318)$ & & & \\
\hline $\begin{array}{l}\text { Vitamin D-binding } \\
\text { protein }\end{array}$ & $\begin{array}{l}\text { P02774; } \\
\text { Q5VZM2 }\end{array}$ & & & & $-0.448(0.0248)$ & & & & \\
\hline $\begin{array}{l}\text { HLA class II } \\
\text { histocompatibility } \\
\text { antigen DP beta } 1 \text { chain }\end{array}$ & P04440 & & & & $-0.447(0.0252)$ & & & & \\
\hline $\begin{array}{l}\text { Extracellular matrix } \\
\text { protein } 1\end{array}$ & Q16610 & & & & $-0.438(0.0286)$ & & & & \\
\hline Ceruloplasmin & P00450 & & & & $-0.437(0.0289)$ & & & & \\
\hline Beta-Ala-His dipeptidase & Q96KN2 & & & & $-0.425(0.0341)$ & & & & \\
\hline $\begin{array}{l}\text { Keratin type II } \\
\text { cytoskeletal } 1\end{array}$ & P04264 & & & & $-0.409(0.0422)$ & & & & \\
\hline $\begin{array}{l}\text { Thyroxine-binding } \\
\text { globulin }\end{array}$ & P05543 & & & & $-0.574(0.0027)$ & $-0.509(0.0093)$ & & \begin{tabular}{|l|}
-0.463 \\
$(0.0197)$
\end{tabular} & \\
\hline $\begin{array}{l}\text { Pregnancy-specific beta- } \\
\text { 1-glycoprotein } 9\end{array}$ & Q00887 & & & & & $0.483(0.0145)$ & $0.475(0.0164)$ & & \\
\hline $\begin{array}{l}\text { ADP-ribosyl cyclase/ } \\
\text { cyclic ADP-ribose } \\
\text { hydrolase } 2\end{array}$ & Q10588 & & & & & $0.433(0.0308)$ & & $0.588(0.0020)$ & \\
\hline
\end{tabular}




\begin{tabular}{|c|c|c|c|c|c|c|c|c|c|}
\hline Protein & Accession & АMH & Androstenedione & Testosterone & Progesterone & Estradiol & Estriol & Estrone & $\begin{array}{l}\text { Estrone-3- } \\
\text { sulphate }\end{array}$ \\
\hline $\begin{array}{l}\text { Complement component } \\
\text { C8 beta chain }\end{array}$ & P07358 & & & & & $-0.411(0.0414)$ & & & \\
\hline $\begin{array}{l}\text { Complement Clr } \\
\text { subcomponent-like } \\
\text { protein }\end{array}$ & Q9NZP8 & & & & & & $0.440(0.0278)$ & & \\
\hline Actin cytoplasmic 1 & & & & & & & $0.406(0.0442)$ & & \\
\hline $\begin{array}{l}\text { Alpha-1- } \\
\text { antichymotrypsin }\end{array}$ & P01011 & & & & & & & \begin{tabular}{|l|}
-0.463 \\
$(0.0198)$
\end{tabular} & \\
\hline $\begin{array}{l}\text { Pregnancy-specific beta- } \\
\text { 1-glycoprotein } 1\end{array}$ & P11464 & & & & & & & $0.449(0.0242)$ & \\
\hline $\begin{array}{l}\text { Pregnancy-specific beta- } \\
\text { 1-glycoprotein } 5\end{array}$ & Q15238 & & & & & & & & \begin{tabular}{|l|}
0.477 \\
$(0.0158)$
\end{tabular} \\
\hline
\end{tabular}

Table 3. Correlation analysis results for clinical parameters and protein abundances detected by LC-MS. Presented as correlation coefficient (p-value).

In this study, data independent acquisition in the UDMSE mode analysis of clinical samples by LC-MS was used. Some of the reasons it was chosen it over ELISA- type orthogonal methods include the superior selectivity, reproducibility and multiplexing of mass spectrometric methods. Other reasons include higher throughput, cost-per-sample and sensitivity compared to immunoassays. However, due to very high dynamic range of serum/plasma proteome, it becomes necessary to deplete high-abundant proteins before processing samples for MS analysis. It introduces a confounding factor when considering validation by orthogonal methods due to the non-selective partial depletion of other proteins; however, current commercially available kits for high-abundant protein depletion are robust enough to maintain high inter-assay reproducibility. The same cannot be said for concordance between immunoassay and LC-MS assays. Regarding the statistical data analysis, reproducibility of selecting biomarkers for differentiating cases from controls is best achieved by a combination of unsupervised and supervised methods. A balanced combination of both of these method types in the form of the PCA, OPLS-DA and ROC curve analysis has been used. Whether a proteomic signature can separate the clinical groups in question is best determined using unsupervised methods, such as the PCA, but to identify important features of interest, supervised methods, such as the OPLS-DA are more suitable. Unsupervised methods serve as a guide regarding whether to use supervised methods or not because using supervised methods alone produces the risk of over-fitting the model.

In addition to the strengths, the study has some limitations. The pilot nature of the study is acknowledged as only seven women with PCOS were included in the analysis. Analyses of larger sample sets are thus warranted in the future. The cases were identified based on hospital records retrospectively and thus we had no contact with them before pregnancy. This population based approach does, however, also reduce selection bias, as the study population is not selected from patients from fertility clinics. The information collected during pregnancy was limited to the data collected from public health care and thus no data were available on insulin sensitivity of the subjects or weight of the placentas, for example. Placental samples were not available for in vitro studies and thus it was not possible to investigate how factors identified in this study affect placental function. In addition, all samples were from term uncomplicated pregnancies of non-obese women. Whether changes similar to the ones detected can be observed in obese women with PCOS or in samples obtained from early pregnancy requires further investigation.

Finally, it is hypothesized that the increased plasma levels of properdin and other circulating thromboinflammatory factors may indicate defective placental function or by themselves induce pathological changes that lead to increased incidence of pregnancy-related hypertensive disorders in women with PCOS. The finding that healthy pregnant women with PCOS display altered plasma proteome even during uncomplicated pregnancies may also reflect an increased risk for metabolic morbidity later in life. Future studies comparing systemic and placental expression of the biomarkers are essential for confirmation of these hypotheses.

\section{Methods}

Patients. The plasma samples were obtained from women who participated in the 'Biology, Affect, Stress, Imaging, and Cognition in pregnancy and the puerperium' (BASIC) cohort ${ }^{20,30,46,47}$. In Uppsala County, Sweden, all pregnant women are invited to participate in the population based BASIC cohort during their routine ultrasound at gestational week 16-18. The eligibility criteria are: 1.) ability to communicate in Swedish, 2.) age $>18$ years and 3.) free from blood-borne diseases. The BASIC cohort covers around $23 \%$ of the women in the Uppsala county area. Brief demographic data are collected upon inclusion (e.g. on chronic disorders, ongoing medication, smoking in early pregnancy, height and weight). The samples used in this study were collected during years 20102012. The women with PCOS were identified from the cohort from the hospital register by the ICD-10 diagnosis of polycystic ovary syndrome (E282). The women were diagnosed according to the Rotterdam criteria, meaning that at least two of the following criteria were present: (1) polycystic ovaries by ultrasonography, (2) oligo- or amenorrhoee and (3) hyperandrogenism, either biochemical (elevated testosterone, androstenedione or elevated free androgen index) or clinical (hirsutism, Ferriman-Gallwey score $>8$ ). The controls were healthy pregnant women matched for age and pre-pregnancy BMI and they had no records for PCOS diagnosis, menstrual irregularities or ovulatory infertility. Placental sample slides from the pregnancies were examined by a pathologist and no abnormalities were detected in either group. 
The women provided written informed consent for inclusion and the study has been approved by the Regional Ethical Review Board (Uppsala, Sweden) and the Regional Ethical Committee of Northern Osthrobothnia Hospital District (Oulu, Finland). The study is compliant with the Declaration of Helsinki.

Plasma sample collection. Upon admission to the delivery ward at the Uppsala county hospital, the only delivery ward in the area, a venous blood sample was drawn into a Lithium-Heparin tube. The plasma samples were stored at $-70^{\circ} \mathrm{C}$.

Plasma sample processing. Plasma samples were processed essentially as described previously ${ }^{48,49}$. Briefly, the top 12 most abundant proteins of plasma were depleted by a TOP 12 depletion kit (Pierce, Thermo Fisher) from $10 \mu \mathrm{L}$ plasma according to the manufacturer's instructions. Depleted plasma was used for estimating the protein amount by a BRADFORD MX reagent (EXPEDION) and an equal amount of protein per sample was dried and resuspended in $50 \mathrm{mM}$ Tris buffer containing $6 \mathrm{M}$ urea (pH 7.8). Dithiothreitol (DTT) was added to final concentration of $10 \mathrm{mM}$ and sample tubes shaken for $1 \mathrm{~h}$ at RT. Iodoacetamide was then added to final concentration of $40 \mathrm{mM}$ and tubes shaken for $1 \mathrm{~h}$ at RT. DTT $(40 \mathrm{mM})$ was then used to quench excess IAA for $1 \mathrm{~h}$ at RT with shaking. Trypsin was the added to the protein mixtures at a trypsin:protein ratio of 1:50 and the samples were incubated at $37^{\circ} \mathrm{C}$ overnight. Resulting tryptic peptides were cleaned with $\mathrm{C} 18$ spin columns according to the manufacturer's instructions.

UDMSE and data analysis. A total of $500 \mathrm{ng}$ of peptides per samples were injected into the nano Acquity UPLC (Ultra Performance Liquid Chromatography) - system (Waters Corporation, MA, USA). TRIZAIC nanoTile $85 \mu \mathrm{m} \times 100 \mathrm{~mm}$ HSS-T3u wTRAP was used for the on-line liquid chromatographic separation of the peptide mixture before being analysed by a mass spectrometer. Samples were loaded, trapped and washed for $2 \mathrm{~min}$ with $8.0 \mu \mathrm{L} / \mathrm{min}$ with $1 \% \mathrm{~B}$. The analytical gradient used was as follows: $0-1 \mathrm{~min} 1 \% \mathrm{~B}$, at $2 \mathrm{~min} 5 \% \mathrm{~B}$, at $65 \mathrm{~min}$ $30 \% \mathrm{~B}$, at $78 \mathrm{~min} 50 \% \mathrm{~B}$, at $80 \mathrm{~min} 85 \% \mathrm{~B}$, at $83 \mathrm{~min} 85 \% \mathrm{~B}$, at $84 \mathrm{~min} 1 \% \mathrm{~B}$ and at $90 \mathrm{~min} 1 \% \mathrm{~B}$ with $450 \mathrm{~nL} / \mathrm{min}$. Buffer A: $0.1 \%$ formic acid in water and Buffer B: $0.1 \%$ formic acid in acetonitrile.

Data were acquired in data independent acquisition mode using UDMSE with Synapt G2-Si HDMS (Waters Corporation, MA, USA). The data were collected for $100-2000 \mathrm{~m} / \mathrm{z}$, with a scan time of one-second, and a IMS wave velocity of $650 \mathrm{~m} / \mathrm{s}$, and collision energy was ramped in trap between 20 and $60 \mathrm{~V}$. Calibration was performed using Glu1-Fibrinopeptide B MS2 fragments and as a lock mass, the Leucine-Enkephaline ion ( $\mathrm{m} / \mathrm{z}$ 556.2771) was used during the runs. The samples were run as triplicates, and further analyses were done using Progenesis QI for Proteomics software (Nonlinear Dynamics, Newcastle, UK).

The data analysis was performed as previously described ${ }^{48,49}$. Briefly, the raw files were imported to Progenesis QI for Proteomics software (Nonlinear Dynamics, Newcastle, UK) using lock mass correction. Default parameters for peak picking and the alignment algorithm were used. Progenesis software facilitated peptide identification with Protein Lynx Global Server and label-free quantification ${ }^{50}$. Peptide identification was done against Uniprot human FASTA sequences (UniprotKB Release 2017_03, 20183 sequence entries) with (CLPB_ECOLI (P63285)), and the $\mathrm{ClpB}$ protein sequence was inserted for label-free quantification. The modifications used included fixed modification of cysteine (carbamidomethyl) and variable modification of methionine (oxidation). Trypsin was the digesting agent with two missed cleavages allowed. Fragment and peptide error tolerances were set to auto, and the FDR to less than $1 \%$. One or more ion fragments per peptide, three or more fragments per protein and one or more peptides per protein were needed for ion matching.

The identified proteins were grouped based on the parsimony principle, and unique peptides to the protein are reported. The parsimony principle governs the rule that protein hits are reported as the minimum set that explains all observable peptides. Progenesis QI for Proteomics software does not take a strict parsimonious approach due to the over-stringency as described previously ${ }^{51}$; however, for the resolution of conflicts, if two proteins contain some common peptides, the protein with fewer peptides is grouped with the protein with a higher number of peptides which are a superset of the subsumed protein's peptides. The lead protein is the one with the greatest coverage or the highest score when the coverages of two or more proteins are the same. Lead identity peptide data are always used for quantitation, and further details regarding this approach are given on the software website (www.nonlinear.com).

Statistics. Hierarchical clustering and self-organising maps (SOM) clustering were performed by R programming as described previously ${ }^{52,53}$. Briefly, SOM clustering was performed on data consisting of X number of samples using R package SOM with parameters ( $. x \operatorname{dim}=5, y \operatorname{dim}=6$, topol = "hexa", neigh = "gaussian"). Data were centred and scaled before performing the clustering. The hclust function in $\mathrm{R}$ was used for generating the heatmaps. MetaboAnalyst 4.0 (https://www.metaboanalyst.ca/) was used for generating individual and combined ROC curves and calculating area under the curve (AUC) values ${ }^{21}$. A non-parametric Mann-Whitney test was performed on cases vs. controls and 0.05 was set as the cut-off for p-value. Principal component analysis was performed using Progenesis QI for Proteomics (v4.0). Orthogonal projections for latent structures-discriminant analysis (OPLS-DA) giving S-Plot was generated by the EZInfo 3.0 software with default parameters. Proteomics data were pareto scaled prior to OPLS-DA modelling. The script that was used to calculate Pearson correlation coefficients and $\mathrm{p}$ values to demonstrate the correlation between hormone values and protein expression can be found in supplementary information. Calculations were performed in R programming language.

\section{Data availability}

The mass spectrometry proteomics data have been deposited into the ProteomeXchange Consortium via the PRIDE $^{54}$ partner repository with the dataset identifiers PXD012034 and 10.6019/PXD012034. 
Received: 23 May 2019; Accepted: 25 October 2019;

Published online: 26 November 2019

\section{References}

1. Teede, H. J. et al. Recommendations from the international evidence-based guideline for the assessment and management of polycystic ovary syndrome. Hum. Reprod. 33, 1602-1618, https://doi.org/10.1093/humrep/dey256 (2018).

2. Skiba, M. A., Islam, R. M., Bell, R. J. \& Davis, S. R. Understanding variation in prevalence estimates of polycystic ovary syndrome: a systematic review and meta-analysis. Hum. Reprod. Update, dmy022-dmy022, https://doi.org/10.1093/humupd/dmy022 (2018).

3. March, W. A. et al. The prevalence of polycystic ovary syndrome in a community sample assessed under contrasting diagnostic criteria. Hum. Reprod. 25, 544-551, https://doi.org/10.1093/humrep/dep399 (2010).

4. Bozdag, G., Mumusoglu, S., Zengin, D., Karabulut, E. \& Yildiz, B. O. The prevalence and phenotypic features of polycystic ovary syndrome: a systematic review and meta-analysis. Human Reproduction 31, 2841-2855, https://doi.org/10.1093/humrep/dew218 (2016).

5. Torchen, L. C. Cardiometabolic Risk in PCOS: More than a Reproductive Disorder. Curr. Diab Rep. 137-017 17, 0956-2, https://doi. org/10.1007/s11892-017-0956-2 (2017).

6. Gonzalez, F. Nutrient-Induced Inflammation in Polycystic Ovary Syndrome: Role in the Development of Metabolic Aberration and Ovarian Dysfunction. Semin. Reprod. Med. 33, 276-286, https://doi.org/10.1055/s-0035-1554918 (2015).

7. Bahri Khomami, M. et al. Increased maternal pregnancy complications in polycystic ovary syndrome appear to be independent of obesity-A systematic review, meta-analysis, and meta-regression. Obes. Rev. 20, 659, https://doi.org/10.1111/obr.12829 (2019).

8. Bahri Khomami, M. et al. The role of maternal obesity in infant outcomes in polycystic ovary syndrome-A systematic review, metaanalysis, and meta-regression. Obes. Rev. 20, 842, https://doi.org/10.1111/obr.12832 (2019).

9. Palomba, S. et al. Pregnancy complications in women with polycystic ovary syndrome. Hum. Reprod. Update 21, 575-592, https:// doi.org/10.1093/humupd/dmv029 (2015).

10. Koster, M. P. et al. Placental characteristics in women with polycystic ovary syndrome. Hum. Reprod. 30, 2829-2837, https://doi. org/10.1093/humrep/dev265 (2015).

11. Palomba, S. et al. Macroscopic and microscopic findings of the placenta in women with polycystic ovary syndrome. Hum. Reprod. 28, 2838-2847, https://doi.org/10.1093/humrep/det250 (2013).

12. Insenser, M., Martinez-Garcia, M. A., Montes, R., San-Millan, J. L. \& Escobar-Morreale, H. F. Proteomic analysis of plasma in the polycystic ovary syndrome identifies novel markers involved in iron metabolism, acute-phase response, and inflammation. J. Clin. Endocrinol. Metab. 95, 3863-3870, https://doi.org/10.1210/jc.2010-0220 (2010).

13. Ma, X. et al. Proteomic analysis of human ovaries from normal and polycystic ovarian syndrome. MHR: Basic science of reproductive medicine 13, 527-535, https://doi.org/10.1093/molehr/gam036 (2007).

14. Ambekar, A. S. et al. Proteomics of follicular fluid from women with polycystic ovary syndrome suggests molecular defects in follicular development. J. Clin. Endocrinol. Metab. 100, 744-753, https://doi.org/10.1210/jc.2014-2086 (2015).

15. Cortón, M. et al. Proteomic analysis of human omental adipose tissue in the polycystic ovary syndrome using two-dimensional difference gel electrophoresis and mass spectrometry. Human Reproduction 23, 651-661 (2008).

16. Borro, M. et al. Proteomic analysis of peripheral T lymphocytes, suitable circulating biosensors of strictly related diseases. Clin. Exp. Immunol. 150, 494-501, https://doi.org/10.1111/j.1365-2249.2007.03498.x (2007).

17. Atiomo, W. U., Khalid, S., Ziauddin, A., Tooth, D. \& Layfield, R. Framework for a systems approach to proteomic biomarker profiling in polycystic ovary syndrome. Expert Review of Proteomics 6, 469-499, https://doi.org/10.1586/epr.09.68 (2009).

18. Khan, G. H., Galazis, N., Docheva, N., Layfield, R. \& Atiomo, W. Overlap of proteomics biomarkers between women with preeclampsia and PCOS: a systematic review and biomarker database integration. Hum. Reprod. 30, 133-148, https://doi.org/10.1093/ humrep/deu268 (2015).

19. Cuevas, A. M. \& Germain, A. M. A Failed Pregnancy Stress Test: A New and Under-Recognized Cardiovascular Risk Factor. Curr. Atheroscler. Rep. 13, 285-286, https://doi.org/10.1007/s11883-011-0182-3 (2011).

20. Piltonen, T. T. et al. Circulating antimullerian hormone and steroid hormone levels remain high in pregnant women with polycystic ovary syndrome at term. Fertil. Steril. 111, 588-596.e1 doi:S0015-0282(18)32223-4 [pii] (2019).

21. Chong, J. et al. MetaboAnalyst 4.0: towards more transparent and integrative metabolomics analysis. Nucleic Acids Res. 46, W486-W494, https://doi.org/10.1093/nar/gky310 (2018).

22. Gibson-Helm, M., Teede, H., Dunaif, A. \& Dokras, A. Delayed Diagnosis and a Lack of Information Associated With Dissatisfaction in Women With Polycystic Ovary Syndrome. J. Clin. Endocrinol. Metab. 102, 604-612, https://doi.org/10.1210/jc.2016-2963 (2017).

23. Huang, C. C. et al. Increased platelet factor 4 and aberrant permeability of follicular fluid in PCOS. J. Formos. Med. Assoc., https:// doi.org/10.1016/j.jfma.2018.05.002 (2018).

24. Gidwani, S. et al. Polycystic ovary syndrome influences the level of serum amyloid A and activity of phospholipid transfer protein in HDL(2) and HDL(3). Hum. Reprod. 29, 1518-1525, https://doi.org/10.1093/humrep/deul15 (2014).

25. Scarinci, E. et al. Increased fibulin-1 plasma levels in polycystic ovary syndrome (PCOS) patients: possible contribution to the link between PCOS and cardiovascular risk. J. Endocrinol. Invest. https://doi.org/10.1007/s40618-018-0891-3 (2018).

26. Kim, Y. S. et al. Apolipoprotein A-IV as a novel gene associated with polycystic ovary syndrome. Int. J. Mol. Med. 31, 707-716, https://doi.org/10.3892/ijmm.2013.1250 (2013).

27. Lai, Y. et al. Circulating Zinc-alpha2-glycoprotein levels and Insulin Resistance in Polycystic Ovary Syndrome. Sci. Rep. 6, 25934, https://doi.org/10.1038/srep25934 (2016).

28. Liu, M. et al. Serum levels of TSP-1, NF- $\kappa$ B and TGF- $\beta 1$ in polycystic ovarian syndrome (PCOS) patients in northern China suggest PCOS is associated with chronic inflammation. Clin Endocrinol 83, 913-922, https://doi.org/10.1111/cen.12951 (2015).

29. Sarig, G. \& Brenner, B. Coagulation, inflammation, and pregnancy complications. Lancet 363, 96-97, https://doi.org/10.1016/S01406736(03)15309-3 (2004)

30. Bränn, E., Edvinsson, A., Rostedt Punga, A., Sundström-Poromaa, I. \& Skalkidou, A. Inflammatory and anti-inflammatory markers in plasma: from late pregnancy to early postpartum. Sci. Rep. 9, 1863-018-38304-w, https://doi.org/10.1038/s41598-018-38304-w (2019).

31. Lacroix, M., Kina, E. \& Hivert, M. Maternal/Fetal Determinants of Insulin Resistance in Women During Pregnancy and in Offspring Over Life. Current Diabetes Reports 13, 238-244, https://doi.org/10.1007/s11892-012-0360-x (2013).

32. Ferguson-Smith, A., Cattanach, B. M., Barton, S. C., Beechey, C. V. \& Surani, M. A. Embryological and molecular investigations of parental imprinting on mouse chromosome 7. Nature 351, 667-670, https://doi.org/10.1038/351667a0 (1991).

33. Constancia, M. et al. Placental-specific IGF-II is a major modulator of placental and fetal growth. Nature 417, 945-948, https://doi. org/10.1038/nature00819 (2002).

34. Sibley, C. P. et al. Placental-specific insulin-like growth factor 2 (Igf2) regulates the diffusional exchange characteristics of the mouse placenta. Proc. Natl. Acad. Sci. USA 101, 8204-8208, https://doi.org/10.1073/pnas.0402508101 (2004).

35. Sferruzzi-Perri, A., Owens, J. A., Pringle, K. G., Robinson, J. S. \& Roberts, C. T. Maternal Insulin-Like Growth Factors-I and -II Act via Different Pathways to Promote Fetal Growth. endo 147, 3344-3355, https://doi.org/10.1210/en.2005-1328 (2006).

36. Steegers, E. A. P., von Dadelszen, P., Duvekot, J. J. \& Pijnenborg, R. Pre-eclampsia. The Lancet 376, 631-644, https://doi.org/10.1016/ S0140-6736(10)60279-6 (2010) 
37. Blatt, A. Z., Pathan, S. \& Ferreira, V. P. Properdin: a tightly regulated critical inflammatory modulator. Immunol. Rev. 274, 172-190, https://doi.org/10.1111/imr.12466 (2016).

38. Blatt, A. Z. et al. Properdin-Mediated C5a Production Enhances Stable Binding of Platelets to Granulocytes in Human Whole Blood. J. Immunol. 196, 4671-4680, https://doi.org/10.4049/jimmunol.1600040 (2016).

39. Snyder, M. L., Shields, K. J., Korytkowski, M. T., Sutton-Tyrrell, K. \& Talbott, E. O. Complement protein C3 and coronary artery calcium in middle-aged women with polycystic ovary syndrome and controls. Gynecol. Endocrinol. 30, 511-515, https://doi.org/10 $.3109 / 09513590.2014 .895985$ (2014).

40. Yang, S. et al. Serum complement $\mathrm{C} 3$ has a stronger association with insulin resistance than high-sensitivity C-reactive protein in women with polycystic ovary syndrome. Fertil. Steril. 95, 1749-1753, https://doi.org/10.1016/j.fertnstert.2011.01.136 (2011).

41. Lynch, A. M. \& Salmon, J. E. Dysregulated Complement Activation as a Common Pathway of Injury in Preeclampsia and Other Pregnancy Complications. Placenta 31, 561-567, https://doi.org/10.1016/j.placenta.2010.03.010 (2010).

42. Girirajan, S. et al. Refinement and discovery of new hotspots of copy-number variation associated with autism spectrum disorder. Am. J. Hum. Genet. 92, 221-237, https://doi.org/10.1016/j.ajhg.2012.12.016 (2013).

43. Cherskov, A. et al. Polycystic ovary syndrome and autism: A test of the prenatal sex steroid theory. Transl. Psychiatry. 8, 136-0180186-7, https://doi.org/10.1038/s41398-018-0186-7 (2018).

44. Chao, J., Bledsoe, G. \& Chao, L. Protective Role of Kallistatin in Vascular and Organ Injury. Hypertension (Dallas, Tex.: 1979) 68, 533-541, https://doi.org/10.1161/HYPERTENSIONAHA.116.07861 (2016).

45. Ceperuelo-Mallafre, V. et al. Circulating and adipose tissue gene expression of zinc-alpha2-glycoprotein in obesity: its relationship with adipokine and lipolytic gene markers in subcutaneous and visceral fat. J. Clin. Endocrinol. Metab. 94, 5062-5069, https://doi. org/10.1210/jc.2009-0764 (2009).

46. Iliadis, S. et al. Corticotropin-releasing hormone and postpartum depression: A longitudinal study. Psychoneuroendocrino Nov, 61 (2015).

47. Kallak, T. K. et al. Maternal and female fetal testosterone levels are associated with maternal age and gestational weight gain. Eur. J. Endocrinol. 177, 379-388, https://doi.org/10.1530/EJE-17-0207 (2017).

48. Saraswat, M. et al. Human Spermatozoa Quantitative Proteomic Signature Classifies Normo- and Asthenozoospermia. Mol. Cell. Proteomics 16, 57-72, https://doi.org/10.1074/mcp.M116.061028 (2017).

49. Saraswat, M. et al. Comparative proteomic profiling of the serum differentiates pancreatic cancer from chronic pancreatitis. Cancer Medicine 6, 1738-1751, https://doi.org/10.1002/cam4.1107 (2017).

50. Silva, J. C., Gorenstein, M. V., Li, G. Z., Vissers, J. P. \& Geromanos, S. J. Absolute quantification of proteins by LCMSE: a virtue of parallel MS acquisition. Mol. Cell. Proteomics 5, 144-156, https://doi.org/10.1074/mcp.M500230-MCP200 (2006).

51. Serang, O., Moruz, L., Hoopmann, M. R. \& Kall, L. Recognizing uncertainty increases robustness and reproducibility of mass spectrometry-based protein inferences. J. Proteome Res. 11, 5586-5591, https://doi.org/10.1021/pr300426s (2012).

52. Joenvaara, S. et al. Quantitative N-glycoproteomics reveals altered glycosylation levels of various plasma proteins in bloodstream infected patients. PLoS One 13, e0195006, https://doi.org/10.1371/journal.pone.0195006 (2018).

53. Saraswat, M., Mäkitie, A., Agarwal, R., Joenväärä, S. \& Renkonen, S. Oral squamous cell carcinoma patients can be differentiated from healthy individuals with label-free serum proteomics. Br. J. Cancer 117, 376 (2017).

54. Vizcaino, J. A. et al. 2016 update of the PRIDE database and its related tools. Nucleic Acids Res. 44, D447-56, https://doi.org/10.1093/ nar/gkv1145 (2016)

\section{Acknowledgements}

We thank the research nurse Elina Huikari for helping with the samples. The work was supported by the Sigrid Juselius Foundation, Academy of Finland, Finnish Medical Foundation and the Northern Osthrobothnia Regional Fund.

\section{Author contributions}

R.K.A. and T.P. designed the study; R.K.A., M.S. and T.P. wrote the manuscript; M.K. was responsible for the sample coordination; I.S.-P. provided patient samples and clinical data; T.T. and M.S. prepared the samples; M.S. and S.J. performed mass spectrophotometry and data analyses; R.A. conducted the Hierarchical clustering and SOM clustering analyses; S.J., R.R. and T.P. revised the paper. All authors reviewed the manuscript.

\section{Competing interests}

The authors declare no competing interests.

\section{Additional information}

Supplementary information is available for this paper at https://doi.org/10.1038/s41598-019-54067-4.

Correspondence and requests for materials should be addressed to T.T.P.

Reprints and permissions information is available at www.nature.com/reprints.

Publisher's note Springer Nature remains neutral with regard to jurisdictional claims in published maps and institutional affiliations.

Open Access This article is licensed under a Creative Commons Attribution 4.0 International License, which permits use, sharing, adaptation, distribution and reproduction in any medium or format, as long as you give appropriate credit to the original author(s) and the source, provide a link to the Creative Commons license, and indicate if changes were made. The images or other third party material in this article are included in the article's Creative Commons license, unless indicated otherwise in a credit line to the material. If material is not included in the article's Creative Commons license and your intended use is not permitted by statutory regulation or exceeds the permitted use, you will need to obtain permission directly from the copyright holder. To view a copy of this license, visit http://creativecommons.org/licenses/by/4.0/.

(C) The Author(s) 2019 